usual pattern of stating his case clearly from the beginning. In the Preface he shows that he is limiting this broad topic to 2 perspectives, namely developmental and epidemiological. He states, 'My main aim in this monograph is to review the evidence on each of these issues and in doing so to speculate on the implications for services'. The contents are then divided into 5 sections, namely Patterns of Adolescent Development and Disorder, Historical Trends in Adolescent Behaviour, Influences on Adolescent Disorder, Changes in Society and the Family, and finally, Services: Implications and Speculations.

Professor Rutter keeps to his brief and provides a masterly coverage of the topic. It is somewhat indigestible in that each page is crammed with facts but every reader will learn from this book. Although only 294 pages the reader will need to allocate plenty of time to absorb the information available. It is excellent value for money but very much a book for the postgraduate and will act as a worthwhile reference book for both clinicians and those involved in lecturing.

\section{Drugs in Anaesthetic Practice}

By M. D. Vickers, F. G. Wood-Smith and H. C. Stewart. 5th edn. Pp. xviii +604, illustrated. Butterworths, London, Boston, Sydney, Wellington, Durban, Toronto, 1978. £16.95.

The reviewer has lived with 'Drugs in Anaesthetic Practice' for the past 6 weeks, having been given the chance to practise anaesthesia in unfamiliar surroundings. The book has virtues, but it also has significant deficiencies.

On the positive side, the general sections and the introductory sections to groups of drugs are interesting and informative. The monographs on individual drugs are, however, uneven and the relative length might be disputed. The importance of a particular drug must always be a matter of subjective judgment, but there is a suspicion that the history of 4 editions still has some influence. In some instances, controversial and important issues are not examined. For example, there is a section on the use of $\beta$-blocking drugs in the treatment of dysrhythmias during anaesthesia, but the case for and against discontinuing $\beta$-blockers before anaesthesia and surgery is not argued. There are a few surprising omissions: most anaesthetists will at some time anaesthetize a woman taking an oral contraceptive and the implications of this might have been included. Disopyramide is tantalizingly mentioned on p. 320 , and again on p. 404 , but does not rate a monograph.

When using the book as a reference source in times of stress, some deficiencies of presentation become apparent. It would be most helpful if exactly the same headings could be used in each monograph and in the same order. It is obvious that the inclusion of, say, 'Drug interactions; none', in a large number of monographs would increase bulk and expense, but it could be established that if a heading was omitted, the drug is innocent in respect of that heading. The index is unnecessarily complicated and sometimes deficient. 'T.H.A.M.' does not appear in the general index, nor in the British converter, but does convert in the American list to 'Tromethamine' which does not appear in the general index. There is, however, an informative monograph on p. 566, under the name 'Trihydroxymethylaminomethane' which does, of course, appear in the general index. Information on T.H.A.M. is easier to find in the book's distinguished American competitor. Could not the index and the converters be combined, using different type-faces for different purposes?

The most worrying feature of the book is the inclusion of statements, sometimes almost asides, which are so inaccurate as to make the reader suspicious of the general level of reliability of the text: p. 368, 'Ephedrine is now rarely used for its pressor action'. Apart from dopamine, ephedrine is the only drug that this reviewer has seen used for its pressor action (and he has seen it used frequently) in the last 12 months; p. 315 , '... [Thymin] in some way is able to diminish the presynaptic storage and release of acetylcholine'. A Registrar preparing for the recent Final F.F.A examination was able accurately to describe only relatively recent work on the production of experimental animal myasthenia by sensitization to acetylcholine receptor, including the name of the snake venom involved; p. 97 (Barbiturate poisoning), 'in some cases, especially if secretions are profuse, tracheostomy is advisable'!!

Finally, do the publishers really believe that the repetition of extracts from eulogistic reviews of previous editions improves the status of the book? 'There is no equal to it in any country in the world and its pages contain some data on every drug which the clinical anaesthetist may encounter'; 'Any country'? 'Every drug'? 'And quite indispensible [wrongly spelt] as a reference in day-to-day practice'. The writer has been in day-to-day practice for almost 33 years and has never, before being asked to review the book, had occasion to open a copy. This may not, of course, preclude the accuracy of the previous reviewer's statement, but it is probably suggestive.

With all its faults, the book should probably find a place in the anaesthetist's 'ready-use locker' beside 'Atkinson, Rushman and Lee', and 'Katz and Kadis', but only if a copy of the distinguished American competitor can be afforded for the central library. The book could, indeed, be made indispensable and it is a pity that it cannot be welcomed without reservation.

\section{EEG Recording}

By M.-L. Hector, 2nd edn. Pp. xii +168 , illustrated (with 85 plates). Butterworths, London, etc., 1980. $£ 9.95$.

Though this is a second and revised edition of Miss Hector's book it is the first edition to be published in English: the translation is good, but occasionally a little awkward.

It is primarily a product of her considerable personal experience, but draws on other contributors for some sections, for example that on EEG in intensive care units.

Without doubt, the best parts of the book deal with practical aspects of making routine records from adults, children and babies; this is the bulk of the text. Interspersed in the main text are occasional illustrative anecdotes, for example one on a puzzling source of artefact recalls the sudden intrusion of mains interference in a previously good record. Close inspection showed that the subject, a baby, had been incontinent of urine as it lay on its mother's lap, and she was sitting with her feet in a puddle.

There are 85 plates of extracts from EEGs with brief apposite legends. The quality of the reproduction in the reviewer's volume is adequate, but finer details have not shown up well in a minority of plates. Many deal with artefacts and they comprise a good cross-section of the common and not so common pitfalls for the uninitiated. Inevitably, there are parts of the subject which are not well treated, and the short section on semi-conductors, for example, says so little that it could have been omitted without loss. There are a few frank errors: time constant is not the time taken for a pen to fall to one third of its initial deflection-this is an approximation and is a bad statement in a section on what are apparently definitions-and there are significant omissions such as the failure to mention the role of methohexitone in a section on pharmacological 'activation' of the EEG. The part dealing with evoked potentials is too brief to be of much use and seems to have been included for the sake of completeness. 